\title{
Digitalization of housing and communal services using the example of apartment buildings
}

\author{
M.Yu. Smirnov ${ }^{1, *}$, V.S. Ziyautdinov ${ }^{1}$, I.V. Voronin ${ }^{1}$, and T.A. Zolotareva ${ }^{1}$ \\ ${ }^{1}$ Lipetsk Cossack Institute of Technology and Management (branch of the Moscow State University \\ of Technology and Management named after K.G. Razumovsky (First Cossack University)), Lipetsk, \\ Russia
}

\begin{abstract}
The possibility of digitalization of housing and communal services is mathematically considered using the example of apartment buildings. The approaches discussed in the paper can be used in the construction of new apartment complexes, as well as in the overhaul of the existing housing stock. In addition, the applied approaches can be easily adapted for use in office buildings and business centers.
\end{abstract}

\section{Introduction}

Improving the quality of service and transparency in the provision of communal services is one of the key tasks of reforming the housing and communal services system. The goal of the national project "HOUSING AND URBAN ENVIRONMENT" is not only to provide affordable housing and improve the comfort of the urban environment, but also a digital transformation and automation of processes, comprehensive improvement of the efficiency of urban infrastructure. First of all, we are talking about improving the energy efficiency of end users [1-6].

Digitization of housing and communal services involves the introduction of applied technologies to automate various processes: forecasting and modeling; accounting for resource consumption; allocation of resources for overhaul, etc. Let us consider one of the approaches to forecasting, modeling and accounting for resource consumption using the example of apartment buildings.

In this paper, a mathematical model for calculating individual heat consumption in a building containing a large number of rooms is proposed and investigated.

\section{Mathematical model}

Let's consider the distribution of heat between rooms that have heating devices connected in series (vertical wiring system, Fig. 1). The figure conventionally shows heating devices (Device 1 - Device 5), temperature sensors $\left(t_{1}-t_{6}\right)$ and a device for determining the amount of energy consumed $(Q)$.

\footnotetext{
* Corresponding author: $\underline{\text { m_u_smirnov@mail.ru }}$
} 


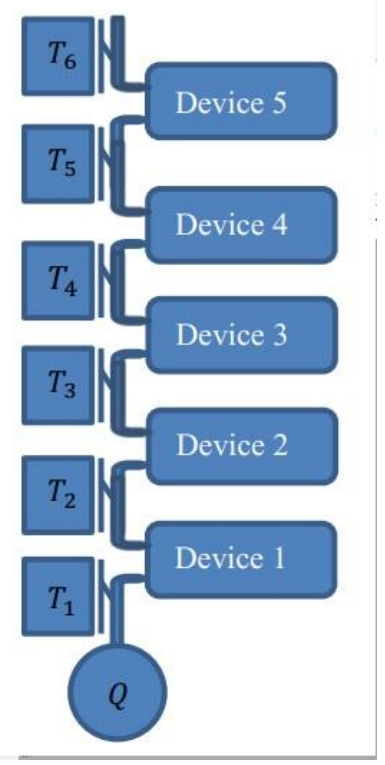

Fig. 1. An example of a heating system for the calculation of individual consumption.

The calculation of the amount of energy consumed from the coolant in a specific heating device can be made according to the well-known formula

$$
Q_{i}=c m \Delta T_{i}
$$

where $c$ - specific heat of thermal energy carrier, $m$ - mass of the heat carrier passed through the heating device, $\Delta T_{i}$ - temperature difference between the heating medium at the inlet and outlet of the heater $\left(\Delta T_{1}=T_{2}-T_{1}, \Delta T_{2}=T_{3}-T_{2}, \ldots, \Delta T_{5}=T_{6}-T_{5}\right.$, for the example shown in fig. 1) [7,8]. The total consumption determined by the meter of $Q$ is also the sum of consumption by heating devices $Q=\sum Q_{i}=c m \sum \Delta T_{i}$. It is easy to obtain individual consumption from the relationship of individual consumption to total consumption:

$$
Q_{i}=Q \frac{\Delta T_{i}}{\sum \Delta T_{i}}
$$

Thus, it turns out that it is quite simple to determine the individual consumption of heat energy from the heating system by the premises.

To implement this approach, it is necessary to provide the heat supply system with the required number of temperature sensors (one more than heating devices) and a general metering device for consumed energy.

A device that can interrogate a system of temperature sensors distributed in space and accumulate information will help automate such a process.

Suppose that the temperature sensors are polled at time intervals $\Delta t_{j}$. Then, with each count, some heat energy of the individual consumer $Q_{j}$ will be obtained. If $N$ counts are received during the time $t$, then the total consumption will be $\sum_{j} Q_{j}$. Therefore, similarly to (2), one can get:

$$
Q_{i}=Q \frac{\sum_{j} \Delta T_{i j}}{\sum_{i, j} \Delta T_{i j}},
$$


where the value $Q$ still reflects the total consumption of all heating devices, and $\Delta T_{i j}$ gives $j$ counting of the temperature difference at the $i$ consumer.

Let's check the correctness of the proposed mathematical model. Let a stationary flow of coolant (water with heat capacity $c=4,19 \cdot 10^{3} \frac{\mathrm{J}}{\mathrm{kg} \cdot{ }^{\circ} \mathrm{C}}$ ) pass through the heating system at the speed $2 \frac{l}{\min }$, the temperature is measured every 5 minutes and for the example shown in Fig. 1 , for the time $1 h$, is presented in table 1 .

Table 1. Measuring the temperature at the inlet and outlet of the heater.

\begin{tabular}{|c|c|c|c|c|c|c|}
\hline $\begin{array}{c}\text { Measurement } \\
\text { number }\end{array}$ & $T_{1},{ }^{\circ} \mathrm{C}$ & $T_{2},{ }^{\circ} \mathrm{C}$ & $T_{3},{ }^{\circ} \mathrm{C}$ & $T_{4},{ }^{\circ} \mathrm{C}$ & $T_{5},{ }^{\circ} \mathrm{C}$ & $T_{6},{ }^{\circ} \mathrm{C}$ \\
\hline $1(t=0$ & 60 & 59 & 58 & 57 & 56 & 55 \\
\hline $2(t=5 \mathrm{~min})$ & 60 & 58 & 57 & 56 & 54 & 52 \\
\hline $3(t=10 \mathrm{~min})$ & 59 & 58 & 56 & 54 & 53 & 52 \\
\hline $4(t=15 \mathrm{~min})$ & 59 & 58 & 56 & 54 & 53 & 52 \\
\hline $5(t=20 \mathrm{~min})$ & 60 & 59 & 58 & 57 & 56 & 55 \\
\hline $6(t=25 \mathrm{~min})$ & 59 & 58 & 56 & 54 & 53 & 52 \\
\hline $7(t=30 \mathrm{~min})$ & 60 & 58 & 57 & 56 & 54 & 52 \\
\hline $8(t=35 \mathrm{~min})$ & 59 & 58 & 56 & 54 & 53 & 52 \\
\hline $9(t=40 \mathrm{~min})$ & 59 & 58 & 56 & 54 & 53 & 52 \\
\hline $10(t=45 \mathrm{~min})$ & 60 & 58 & 57 & 56 & 54 & 52 \\
\hline $11(t=50 \mathrm{~min})$ & 60 & 59 & 58 & 57 & 56 & 55 \\
\hline $12(t=55 \mathrm{~min})$ & 59 & 58 & 56 & 54 & 53 & 52 \\
\hline $13(t=1 \mathrm{~h})$ & 59 & 58 & 56 & 54 & 53 & 52 \\
\hline
\end{tabular}

In accordance with (1), it is possible to determine the total heat consumption by all heating devices in each calculated period of time and the individual energy consumption by each consumer. It should be noted here that in fact, averaging of the consumed energy occurs, since the temperature of the coolant does not remain constant and changes. More accurate calculations will be obtained in the case of a larger number of temperature points or the use of numerical methods for integrating experimentally specified functions $\Delta T(t)$. In this case, the sum over the index $j$ will be transformed into an integral $\sum_{j} \Delta T_{i j} \rightarrow \int_{t_{1}}^{t_{2}} \Delta T_{i} d t$, and instead of formula (3), we get the following expression:

$$
Q_{i}=Q \frac{\int_{t_{1}}^{t_{2}} \Delta T_{i} d t}{\sum_{i} \int_{t_{1}}^{t_{2}} \Delta T_{i} d t}
$$

So, in accordance with (1), we get:

$$
Q=3.6872 M J, Q_{1}=670.4 \mathrm{~kJ}, Q_{2}=838 \mathrm{~kJ}, Q_{3}=838 \mathrm{~kJ}, Q_{4}=670,4 \mathrm{~kJ}, Q_{5}=670,4 \mathrm{~kJ},
$$

and in accordance with (3), assuming the given value $Q$, we obtain the individual consumption of heating devices:

$$
Q_{1}=670.4 \mathrm{~kJ}, Q_{2}=838 \mathrm{~kJ}, Q_{3}=838 \mathrm{~kJ}, Q_{4}=670,4 \mathrm{~kJ}, Q_{5}=670,4 \mathrm{~kJ},(6)
$$

which fully confirms the correctness of the proposed mathematical model. 


\section{Hardware for the implementation of the proposed mathematical model}

The proposed mathematical model can be implemented in an automatic mode in the case of using a device that accumulates information about the temperature modes of operation of heating devices and transmits it to any computing module (computer). The structure of the automatic system is shown in Fig. 2. Here "Controller I" collects temperature data from heating devices and transfers them to a remote server. Each controller serves a specific area of the system. The remote server is an ordinary computer with preinstalled software capable of storing the received information in the form of a database and performing calculations according to the presented mathematical model. The operator starts the calculation of individual consumption and uses the obtained results further. The number of controllers connected to one computer is not limited to those shown in Fig. 2 and depends on the computing capabilities of the system used.

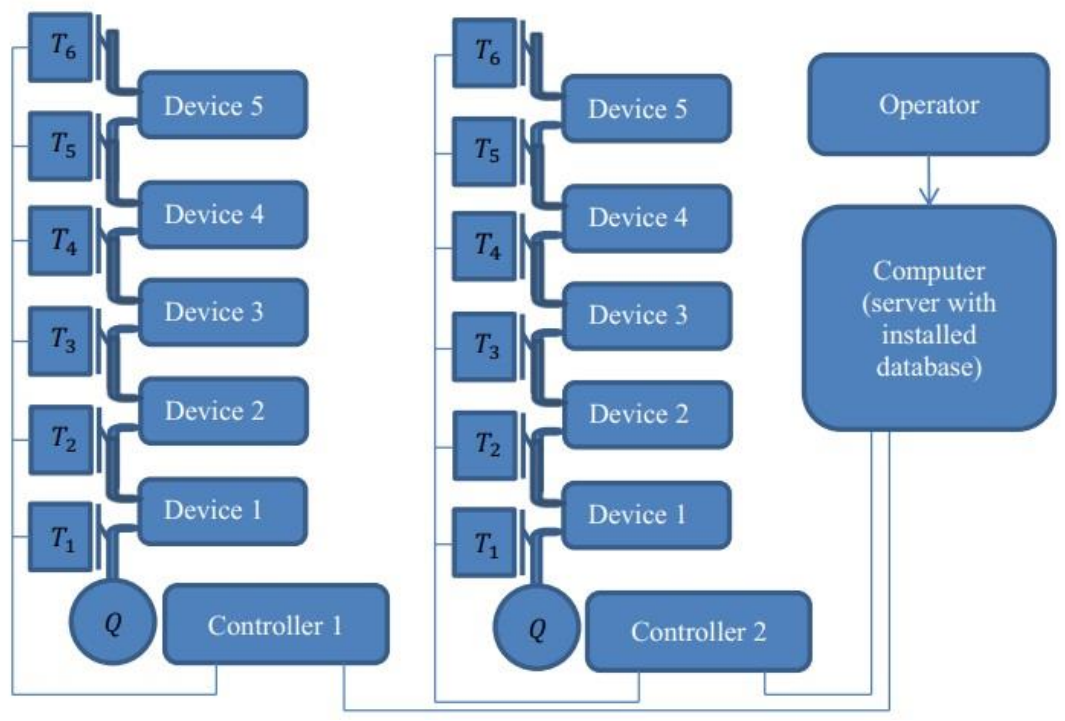

Fig. 2. An example of the implementation of an automatic system for collecting temperature information from heating devices.

In this case, the mathematical model implies the presence of two stages:

- $\quad$ primary accumulation of information from temperature sensors;

- $\quad$ calculation of individual heat consumption according to formula (3) or (4) on a given array of temperature data and the total amount of consumed energy.

To perform the first stage, it is necessary to have a device (in Fig. 2 - a controller) capable of periodically collecting information from a network of temperature sensors distributed in space and sending it to a server that accumulates it in the form of an information database. Such a device can be made on the simplest microcontrollers with low power consumption and sufficient performance for the performed actions. For example, microcontrollers of the STMicroelectronics company [9] or any others can be used, which have a sufficient number of communication interfaces for communication with a network of temperature sensors and with a remote server of a computer.

As temperature sensors, it is most convenient to use digital devices that receive power from a microcontroller and do not require a lot of wiring. Thus, it is recommended to use a 
network with a "common bus" topology, which will simplify the installation of the system: the wire of the network of temperature sensors can be laid parallel to the pipes of the heating system. One of the possible options for implementing a network of distributed sensors will be the use of a single-wire network developed by Maxim Integrated Products, for example, MAX31820 [10], or similar.

Examples of the implementation of the devices described above can be found in [11-15].

The accumulation of information is carried out for some time (depending on the specific requirements of the system user) and, upon request, the individual consumption is calculated.

\section{Algorithm for calculating the individual consumption of heat energy}

In accordance with the above mathematical model, the calculation is performed as follows:

- the difference $\Delta T_{i j}=T_{i}-T_{i+1}$ is determined, where $T_{i}$ is a temperature at the inlet and $T_{i+1}$ at the outlet $i$ of the heater, temperatures correspond to the $j$ count (line-by-line data differences in Table 1);

- calculation by formulas (3) or (4) using the obtained differences $\Delta T_{i j}$ and the value of the total energy consumed by all heating devices.

The calculation according to the above algorithm does not pose any difficulties for a modern electronic computer. The output is the values of individual heat consumption $Q_{i}$.

Consider the algorithms for the above actions. The algorithm for collecting temperature information is a simple cyclical polling of all sensors after a given time interval. This period of time should be at least the polling time of all temperature sensors. The algorithm is shown in Fig. 3.

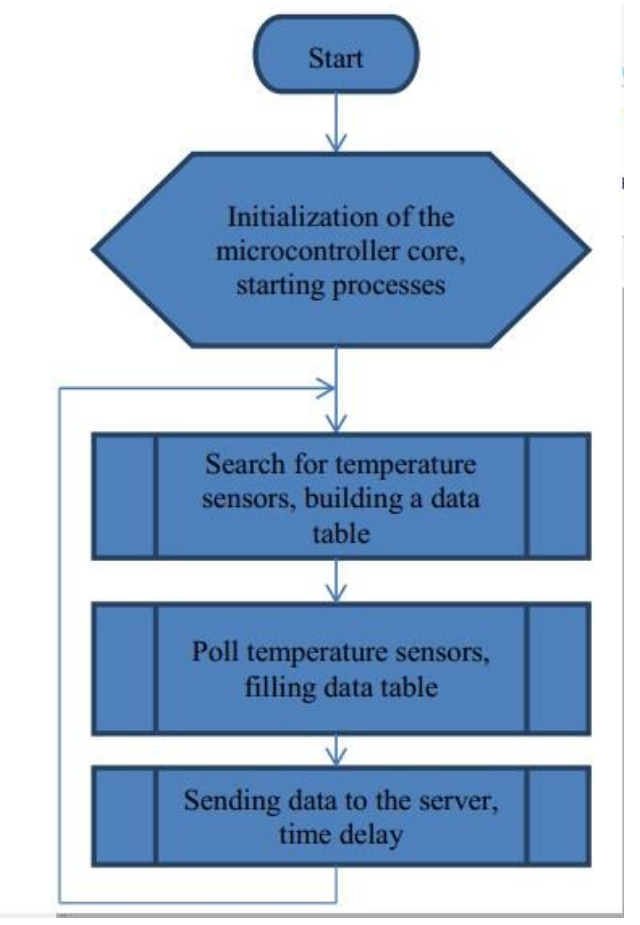

Fig. 3. The algorithm of the controllers. 
To save the data received from the temperature sensors controller, and calculating individual consumption, the computer must be running software that performs the algorithm shown in Fig. 4. In accordance with fig. 2 the operator sets the necessary data for the calculation and starts the calculation for execution. In this case, the server continues to receive and accumulate information from the temperature sensor controllers.

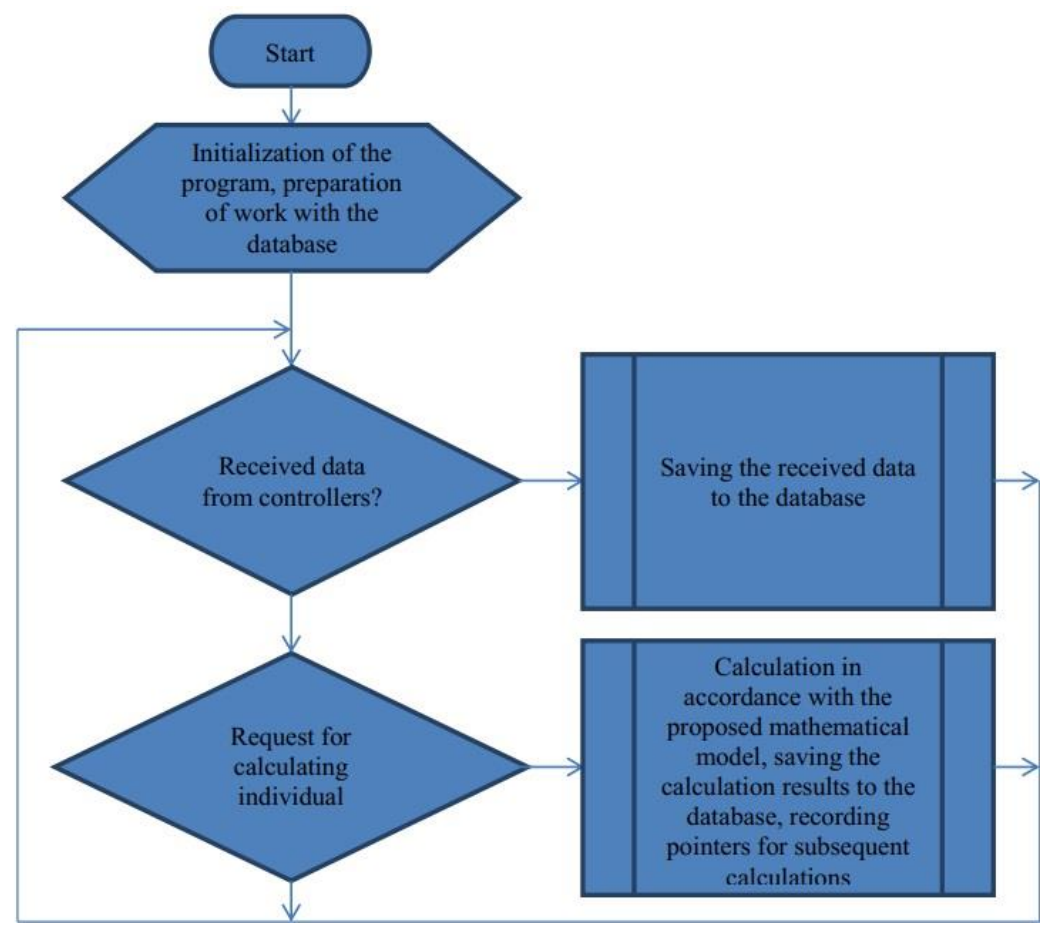

Fig. 4. Algorithm of the software on the server.

\section{Conclusion}

The proposed scheme and model make it possible to receive and process information from the heating system of an apartment building as quickly as possible, take into account resource consumption, work on charges and payments, provide services and individualize informing residents.

First of all, automation will give positive results in the service for residents and increase the energy efficiency of the house, which means reducing the financial costs for citizens.

\section{References}

1. The federal law of July 21, 2014 № 209-FZ «About the state information system of housing and communal services» (with changes and additions) http://basegarantru/70700450/

2. The order of the Government of the Russian Federation from 7/28/2017 № 1632 About the approval of the «Digital Economy of the Russian Federation» program (with changes and additions) http:/ http://basegarantru/71734878/

3. Voevodkin N Yu, Devyaterikova E E 2019 Economy and business: theory and practice 


\section{3-1}

4. Demenko O G, Tikhomirov A O 2018 Russia University Bulletin 559

5. Nalesnaya Y A 2013 Bulletin of the Adygey State University Series 5: Economy 2(120) 201

6. Rabinovich M D 2004 News of heat supply 1049

7. Trofimova T I 2006 Course of physics: textbook for universities (M: Publishing Center “Academy") p 560

8. Saveliev I V 2001 General physics course: textbook manual for students of technical colleges Vol 1: Mechanics Molecular Physics (M: Nauka) p 432

9. DS11853 STM32F722xx STM32F723xx datasheets https://wwwstcom/resource/en/datasheet/stm32f722icpdf

10. MAX31820 1-Wire Ambient Temperature Sensor datasheets https://datasheetsmaximintegratedcom/en/ds/MAX31820pdf

11. Krutikov M A, Smirnov M Yu, Ziyautdinov V S 2020 Fundamentals of design and programming of microcontroller devices (Lipetsk: State Autonomous Institution of Additional Professional Education of the Lipetsk Region "Institute for the Development of Education") p 110

12. Smirnov M Yu, Ziyautdinov V S, Ovechkin D E 2019 On the issue of teaching the basics of design and development of microcontroller devices. Teaching information technology in the Russian Federation p 224

13. Smirnov M Yu, Ovechkin D E 2019 One of the possible implementations of the organization of a distributed network of sensors Information technology in the process of training a modern specialist (Lipetsk: Lipetsk State Pedagogical University named after PP Semyonov-Tyan-Shansky) p 108

14. Smirnov Yu, Skudnev D M, Ovechkin D E 2017 Configuration and sensor management in a distributed collection of information network Computer program RU 2017662904

15. Smirnov M Yu, Ziyautdinov V S, Skudnev D M, Ovechkin D E, Popov T E, Klein D E 2017 A system for collecting and making decisions for a distributed network of sensors and executive devices Computer program RU 2017662906 